Article

\title{
Durability Parameters of Reinforced Recycled Aggregate Concrete: Case Study
}

\author{
S. P. Arredondo-Rea ${ }^{1} \mathbb{1}$, R. Corral-Higuera ${ }^{1, * \mathbb{C}}$, J. M. Gómez-Soberón ${ }^{2}{ }^{\mathbb{D}}$, D. C. Gámez-García ${ }^{2}$,
} J. M. Bernal-Camacho ${ }^{3}$, C. A. Rosas-Casarez ${ }^{1}$ (I) and M. J. Ungsson-Nieblas ${ }^{1}$

1 Universidad Autónoma de Sinaloa, Facultad de Ingeniería Mochis, Fuente de Poseidón y Ángel Flores s/n, Ciudad Universitaria, C.P. 81223 Los Mochis, México; paola.arredondo@uas.edu.mx (S.P.A.-R.); carlos.arc@uas.edu.mx (C.A.R.-C.); manuel_ungsson@hotmail.com (M.J.U.-N.)

2 Universidad Politécnica de Cataluña, Escuela Politécnica Superior de Edificación de Barcelona, Gregorio Marañón 44-50, C.P. 08020 Barcelona, España; josemanuel.gomez@upc.edu (J.M.G.-S.); diana.carolina.gamez@upc.edu (D.C.G.-G.)

3 Universidad Autónoma de Sinaloa, Escuela de Ingeniería Mazatlán, C.P. 82017 Mazatlán, México; jmbc6784@hotmail.com

* Correspondence: ramon.corral@uas.edu.mx

Received: 12 December 2018; Accepted: 4 February 2019; Published: 13 February 2019

\begin{abstract}
Recycled concrete aggregate (RA) from pavement demolition was used to make concrete. Ten concrete mixtures with different replacement percentages of RA (coarse and fine) were made. The corrosion rate of steel and the electrical resistivity of concrete were determined on reinforced concrete specimens subjected to wetting-drying cycles $(3.5 \%$ solution of $\mathrm{NaCl})$. Corrosion rate was determined using the electrochemical technique of linear polarization resistance, while the electrical resistivity was measured by electrochemical impedance spectroscopy. The results show that the use of RA introduces more interfaces in concrete, which accelerates the steel corrosion process because the porosity increases and the electrical resistivity decreases. However, steel corrosion and the electrical resistivity in concrete are not significantly influenced by replacing a maximum $30 \%$ of coarse aggregate or $20 \%$ of fine aggregate with RA.
\end{abstract}

Keywords: recycled concrete aggregates; electrochemical techniques; electrical resistivity; corrosion; porosity

\section{Introduction}

Aggregates constitute approximately $70 \%$ of the volume of a concrete mixture; that is why large amounts of crushed rock, gravel, and sand are being extracted, processed, and transported around the world, generating environmental and economic costs. The use of recycled concrete aggregate (RA) for the production of concrete began at the end of World War II. Debris obtained by the demolition of concrete pavements, roads, and building foundations and structures were satisfactorily reused around the world [1]. It is estimated that more than 10,000 tons of public, private, and industrial construction and demolition waste are generated daily in Mexico [2]. The interest in investigating and using RA to produce new concrete is because concrete is a material that is demanded at the population growth rate and because the use of RA is an alternative to natural aggregates and has potential for exploitation for the great amounts of construction and demolition debris that are generated worldwide annually.

On the other hand, due to the necessity to ensure the durability of reinforced concrete structures-mainly against steel corrosion as it is one of the most frequent diseases-a tendency of incorporating more advanced concepts of durability is observed on the basis of the regulation design. There are many proposals based on the modeling of the attack mechanism for service life 
prediction [3,4]. However, despite the evident importance of taking real properties into account when estimating the durability to prevent significant mistakes in the results, only some of them are based on concrete "performance" and they are called indicators of durability $[5,6]$. One of the durability indicators is the electrical resistivity of concrete $(\rho)$, inverse of conductivity, and it is a volumetric measurement of the electrolytic resistance (Re) of the material, which through Ohm's law is expressed as the ratio of voltage to applied current $(\operatorname{Re}=\mathrm{V} / \mathrm{I})$. It was initially developed in geophysics [7], extensively researched in concrete with different types of cement [8], and is a property that reflects the ability of the porous medium of transporting electrical charge in a finite or semi-infinite volume. The corrosion process of the reinforcement steel is schematized in Figure 1 [9], where the surface of the corroded steel works as a combination electrode that is composed of anodes and cathodes electrically connected through the same steel, upon which a couple of anodic and cathodic reactions occur.

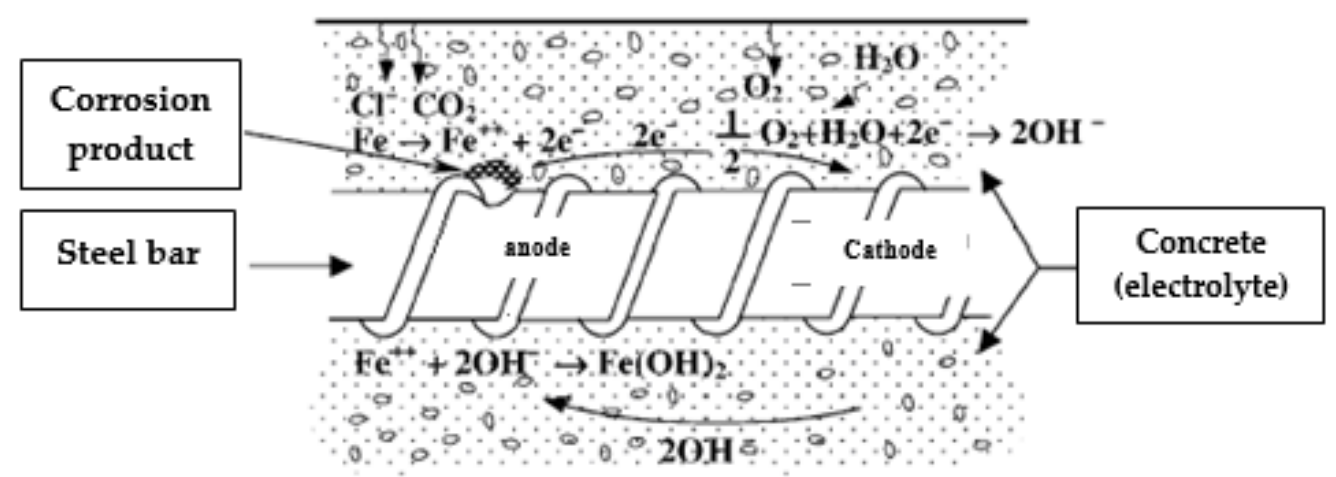

Figure 1. Schematic illustration of corrosion of reinforcement steel in concrete as an electrochemical process.

The pore solution of concrete works as an aqueous medium, that is, an electrolyte through which ions transport electric charge. Thus, $\rho$ emerges as a key parameter in the corrosion process because it reflects the ability of the ions dissolved in the aqueous phase contained in the concrete pores to transport electric charge.

Some research on recycled aggregate concrete (RAC) show that the use of RA increases the porosity of the new concrete [10-12], which it is linked to $\rho$ because it represents the paths for ionic conductivity [13-15]. It is evident, and some investigations have confirmed [16,17], that $\rho$ is inversely proportional to the corrosion current density of the reinforcement steel $\left(\mathrm{i}_{\text {corr }}\right)$ making it a fundamental parameter in the electrochemical corrosion process of steel embedded in concrete. In order to determine the influence that the use of RA (coarse and fine) on the electrical resistivity of concrete and in the corrosion current density of reinforcement steel, these durability parameters were evaluated using electrochemical techniques varying the percentage of recycled fine aggregates (RFA) and recycled coarse aggregates (RCA) contained in the concrete.

\section{Research Significance}

During the last 20 to 30 years different approaches have been taken in practice and research by various researchers. Among them it is observed, for example:

- Replacement of RA by natural aggregates (NA) considering the effect of the difference in density or distribution of particle sizes. In this sense, some researchers have tried to obtain "identical" granulometric profiles, for example, which makes it possible to avoid this variable being imputable in the change of the properties studied. However, this technological requirement in industrial practice on a large scale is obviously unacceptable because of the costs involved in dividing the aggregates into fractions of sizes and then recomposing the ideal profile again. Regarding changes in density, there are experimental procedures that allow separating the old 
mortar fraction from the old natural aggregate, thus allowing the RA to have densities equivalent to those of an NA (but with an equally complicated industrial practice).

- In other new alternatives, some researchers have chosen to use the RA replacing the NA without making specific considerations, and in this sense, its objective has been to establish the increase in cement consumption that is required to "balance" both mixtures. This scientific trend simplifies the industrialized commercial application of recycled concretes, since everything is limited to making increments of cement in the mixtures. However, this type of application has researchers who present important reflections: is it appropriate to use RA in a concrete that is called recycled (and therefore sustainable) when its solution is to use more cement (one of the construction materials) with maximum environmental impact?

Therefore, in the present work, a research proposal was made that is feasible at the local level (practical and real solution) and that is why it was chosen to carry out the experimental work with different dosages.

\section{Materials and Methods}

\subsection{Materials and Mixtures}

The cement used was Portland composite cement (PCC) with 30 MPa of resistance (PCC 30R). Physicochemical requirements are stipulated in the Mexican regulation NMX-C-414 and are equivalent to ordinary Portland cement Type III established in ASTM C150; PCC 30R was chosen because it is commonly used and widely applied in the concrete industry in Mexico. Natural coarse aggregates (NCA) came from a local river, considering a maximum particle size of $25.4 \mathrm{~mm}$, and the natural fine aggregates (NFA) were siliceous river sand. RA came from the crushing of demolished concrete pavements in the city with the characteristics shown in Table 1.

Table 1. Physical properties of old concrete.

\begin{tabular}{cc}
\hline Absorption (\%) & 6.91 \\
\hline Density g/cm ${ }^{3}$ & 2.36 \\
\hline Porosity $\%$ & 17.87 \\
\hline Compressive strength $(\mathrm{MPa})$ & 28.15 \\
\hline
\end{tabular}

The RA consisted of natural aggregate plus adhered mortar, in turn containing cement paste and the original sand. The detailed characterization of the aggregates used and the production process was reported in a previous publication [18].

Physical properties of the aggregates are shown in Table 2, where it can be observed that the RCA and the RFA present an absorption of 5 and 6 times greater than that of the NCA and NFA, respectively. It can also be observed that the density of the recycled aggregates decreases, which is due to the porous mortar adhered to them.

Table 2. Physical characteristics of the aggregates.

\begin{tabular}{lcccc}
\hline & ${ }^{*}$ Density $\left(\mathrm{g} / \mathrm{cm}^{3}\right)$ & ${ }^{*}$ Absorption $\%$ & ${ }^{* *}$ Fineness Modulus & ${ }^{* *}$ Maximum Size $(\mathbf{m m})$ \\
\hline NCA & 2.56 & 1.19 & - & 25.4 \\
\hline NFA & 2.59 & 1.88 & 2.53 & 4.76 \\
\hline RCA & 2.38 & 6.27 & - & 25.4 \\
\hline RFA & 2.28 & 11.86 & 3.38 & 4.76 \\
\hline
\end{tabular}

${ }^{*}$ Standard procedure in ASTM C127 (coarse aggregates) and ASTM C128 (fine aggregates). ${ }^{* *}$ Standard procedure in ASTM C33. NCA: natural coarse aggregates; NFA: natural fine aggregates; RCA: recycled coarse aggregates; RFA: recycled fine aggregates. 
The values of the void ratio, porosity, and therefore hydraulic conductivity, in the case of RA are higher than a natural aggregate [19].

The particle size distribution of the recycled and natural aggregates are shown in Figures 2 and 3.

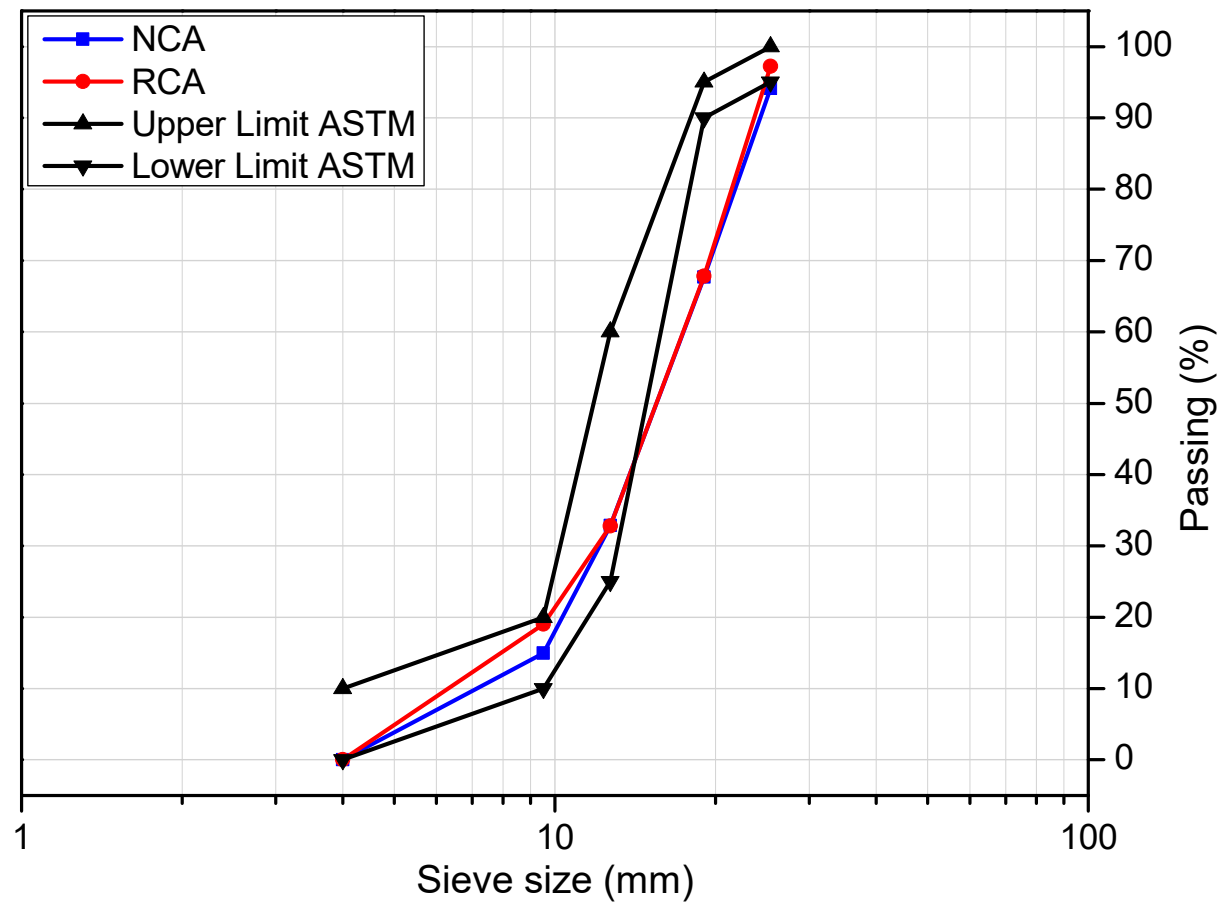

Figure 2. Particle size distribution of coarse aggregates.

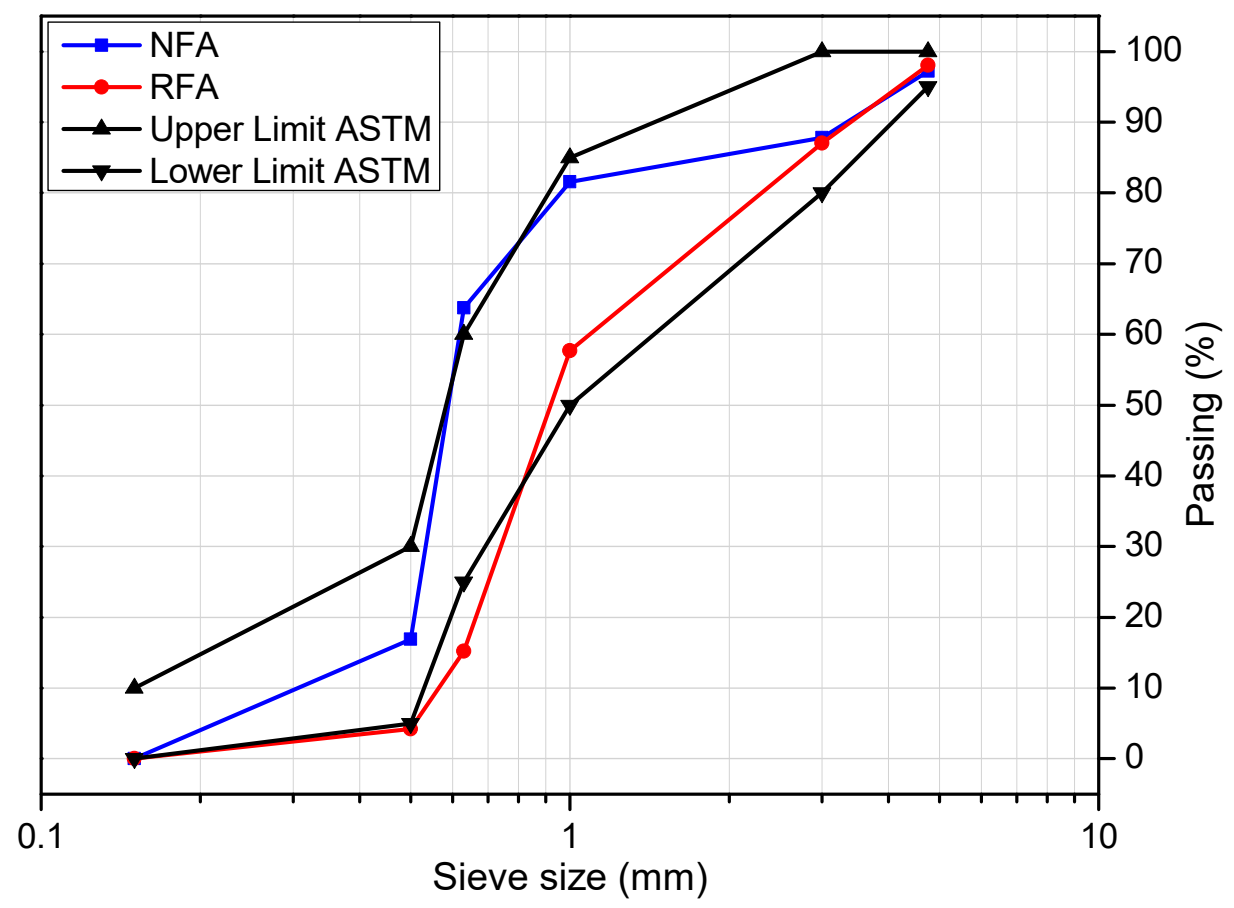

Figure 3. Particle size distribution of fine aggregates.

Ten mixtures were designed with a w/c ratio of 0.5 and with the proportions shown in Table 3. Mixture 1 (NAT) and mixture 10 (RA-100) are reference mixtures, the first one is of conventional concrete (it does not contain RA) while the second one does not contain natural (or conventional) aggregates, that is, it is made with $100 \%$ RCA and RFA. In mixtures 2 to 5, NCA was replaced by the 
RCA in percentages of 20, 30, 60, and 100 (RCA-20, RCA-30, RCA-60, and RCA-100); in mixtures 6 to 9 , NFA was replaced by RFA in percentages of 20, 30, 60, and 100 (RFA-20, RFA-30, RFA-60, and RFA-100).

Table 3. Proportion of the test mixtures. PCC: Portland composite cement.

\begin{tabular}{|c|c|c|c|c|c|c|c|c|c|c|}
\hline \multirow{3}{*}{$\begin{array}{c}\text { Material } \\
\left(\mathrm{kg} / \mathrm{m}^{3}\right)\end{array}$} & \multicolumn{10}{|c|}{ Identification of the mixtures } \\
\hline & 1 & 2 & 3 & 4 & 5 & 6 & 7 & 8 & 9 & 10 \\
\hline & NAT & RCA-20 & RCA-30 & RCA-60 & RCA-100 & RFA-20 & RFA-30 & RFA-60 & RFA-100 & RA-100 \\
\hline Water & 175 & 175 & 175 & 175 & 175 & 175 & 175 & 175 & 175 & 175 \\
\hline NCA & 1050 & 840 & 735 & 420 & 0 & 1050 & 1050 & 1050 & 1050 & 0 \\
\hline RCA & 0 & 210 & 315 & 630 & 1050 & 0 & 0 & 0 & 0 & 1050 \\
\hline NFA & 700 & 700 & 700 & 700 & 700 & 560 & 490 & 280 & 0 & 0 \\
\hline RFA & 0 & 0 & 0 & 0 & 0 & 140 & 210 & 420 & 700 & 700 \\
\hline PCC & 350 & 350 & 350 & 350 & 350 & 350 & 350 & 350 & 350 & 350 \\
\hline
\end{tabular}

\subsection{Methods}

Ten cylindrical specimens $(\phi=10 \mathrm{~cm}, \mathrm{~h}=20 \mathrm{~cm})$ of each one of the mixtures were made subjecting them to standard curing for 28 days by water immersion. The compaction method used was manual rodding. Compressive strength was evaluated on each mixture on three simple concrete specimens under ASTM C39. Total porosity of each concrete mixture was evaluated on six slices of $10 \mathrm{~cm}$ diameter and $5 \mathrm{~cm}$ thickness following the ASTM C642 procedure. Three samples of each type of concrete were dried at $100{ }^{\circ} \mathrm{C}$ in a furnace until constant mass was reached, and dry weight (Wdry) was determined. Then samples were water saturated (boiled for $5 \mathrm{~h}$ and allowed to cool by natural loss of heat for not less than $14 \mathrm{~h}$ to a final temperature of 20 to $25^{\circ} \mathrm{C}$ ). After completing the saturation process, samples were weighted in a hydrostatic scale to determine submerged weight (Wsub). Finally, the surface of the samples was dried and saturated weight (Wsat) was determined. Open porosity was calculated by Equation (1).

$$
\text { Total Porosity }(\%)=\frac{W \text { sat }-W_{\mathrm{dry}}}{\text { Wsat }-W_{\text {sub }}} * 100
$$

To evaluate other durability parameters such as $i_{\text {corr }}$ and $\rho$, a corrugated steel rod was embedded in one cylindrical specimen of each mixture with a $40 \mathrm{~cm}^{2}$ exposed area in the center. After the curing period and to accelerate the process of corrosion, the specimens were subjected to wet-dry weekly cycles (the specimens were submerged in a $3.5 \% \mathrm{NaCl}$ aqueous solution for 3 days for the wet cycles and kept for 4 days in an oven at $40^{\circ} \mathrm{C}$ for the dry cycles).

At the end of the wetting period, the electrochemical tests were carried out in order to determine $\mathrm{i}_{\text {corr }}$ and $\rho$ using the arrangement shown in Figure 4. An ACM Instruments Field Machine potentiostatgalvanostat series 1525, an $\mathrm{Ag} / \mathrm{AgCl}$ (silver/silver chloride) reference electrode (RE), a stainless steel auxiliary electrode (AE), and the reinforcement steel acted as the working electrode (WE).

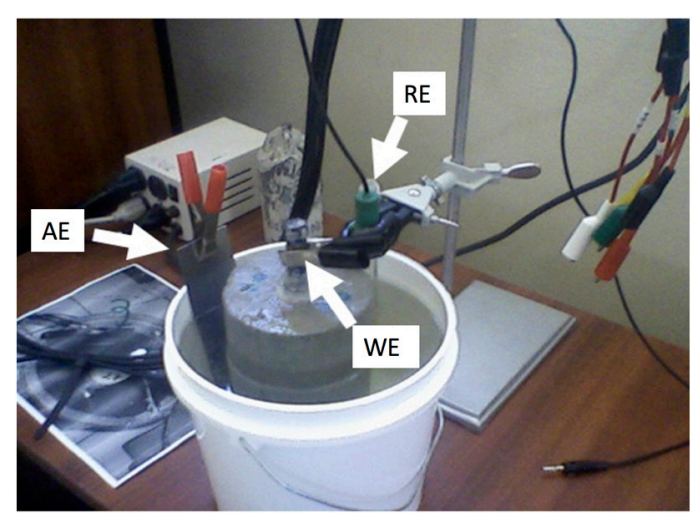

Figure 4. Experimental arrangement for the electrochemical tests. AE: auxiliary electrode; WE: working electrode; RE: reference electrode. 


\subsection{Lineal Polarization Resistance (LPR)}

To determine $i_{\text {corr, }}$ an LPR test was carried out with a swept potential of -20 to $20 \mathrm{mV}$ at a $10 \mathrm{mV} / \mathrm{min}$ speed. Polarization resistance (Rp) was determined using the potential-current curve obtained from the LPR test, taking as the Rp value the gradient of the linear part of the curve, as shown in Figure 5.

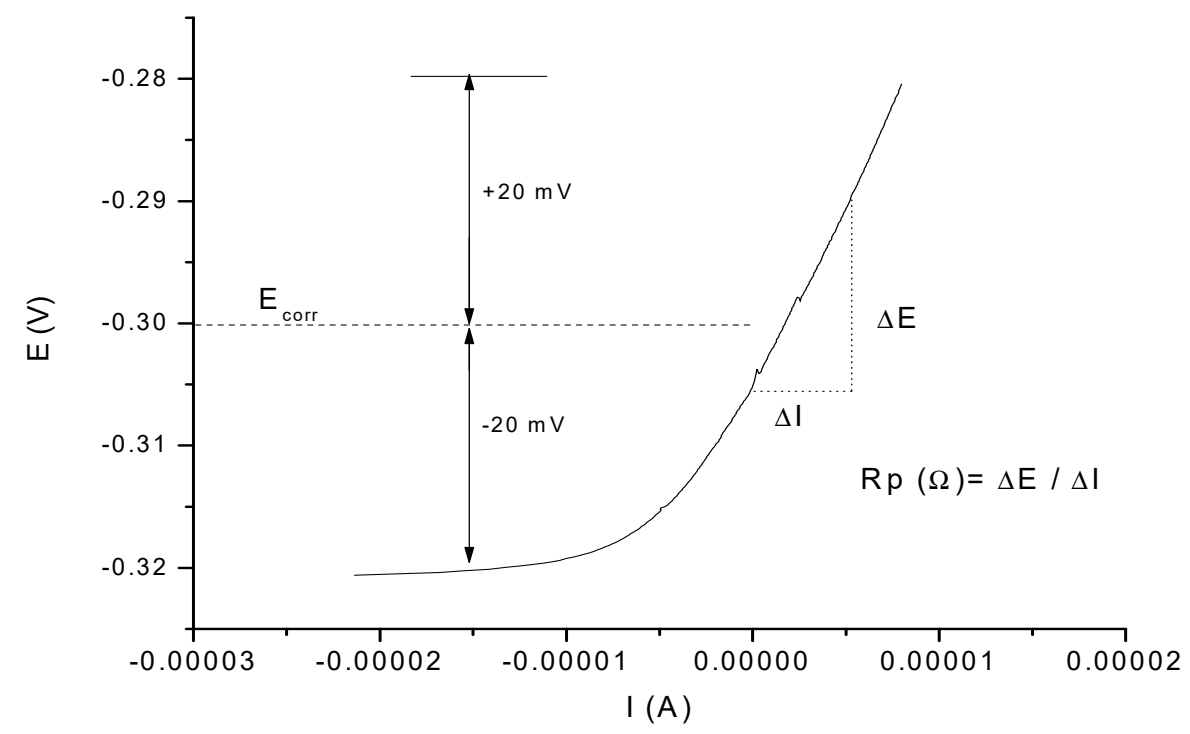

Figure 5. Typical curve of a lineal polarization resistance (LPR) test.

Once Rp was obtained, $i_{\text {corr }}$ was determined using Equation (2) developed by Stern and Geary [20], where $B$ is a Tafel constant that can vary from 0.026 to $0.052 \mathrm{~V}$. For this work, $\mathrm{B}=0.026 \mathrm{~V}$ was considered.

$$
\mathrm{i}_{\text {corr }}=\mathrm{B} / \mathrm{Rp}
$$

\subsection{Electrochemical Impedance Spectroscopy (EIS)}

In order to determine $\rho$, EIS studies were carried out with the testing parameters of $20 \mathrm{mV}$ amplitude to maintain the system linearity in a frequency rate of 100,000 to $0.1 \mathrm{~Hz}$. Electrolytic resistance ( $\mathrm{Re}$ ) was obtained from the change of slope at high frequencies in a Nyquist diagram, as shown in Figure 6. In previous research the use of EIS is well documented to determine $\rho$ [21,22].

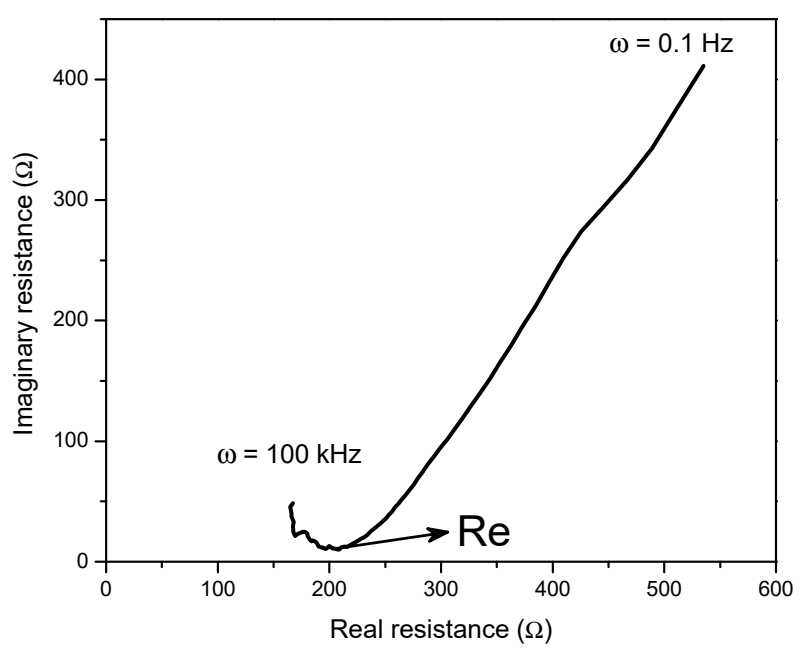

Figure 6. A typical Nyquist diagram of electrochemical impedance spectroscopy (EIS) studies at high frequencies. 
Once Re was obtained, $\rho$ was determined using Equation (3).

$$
\operatorname{Re}=\rho C c ; \rho=\operatorname{Re} / C_{c},
$$

where $\mathrm{Cc}$ is a cell constant which depends on the geometry and conditions of the conducting body [23]. For this work, $\mathrm{C} c=1$ was considered.

\section{Results and Discussion}

\subsection{Compressive Strength}

Compressive strength of the different studied mixtures is shown in Figure 7.

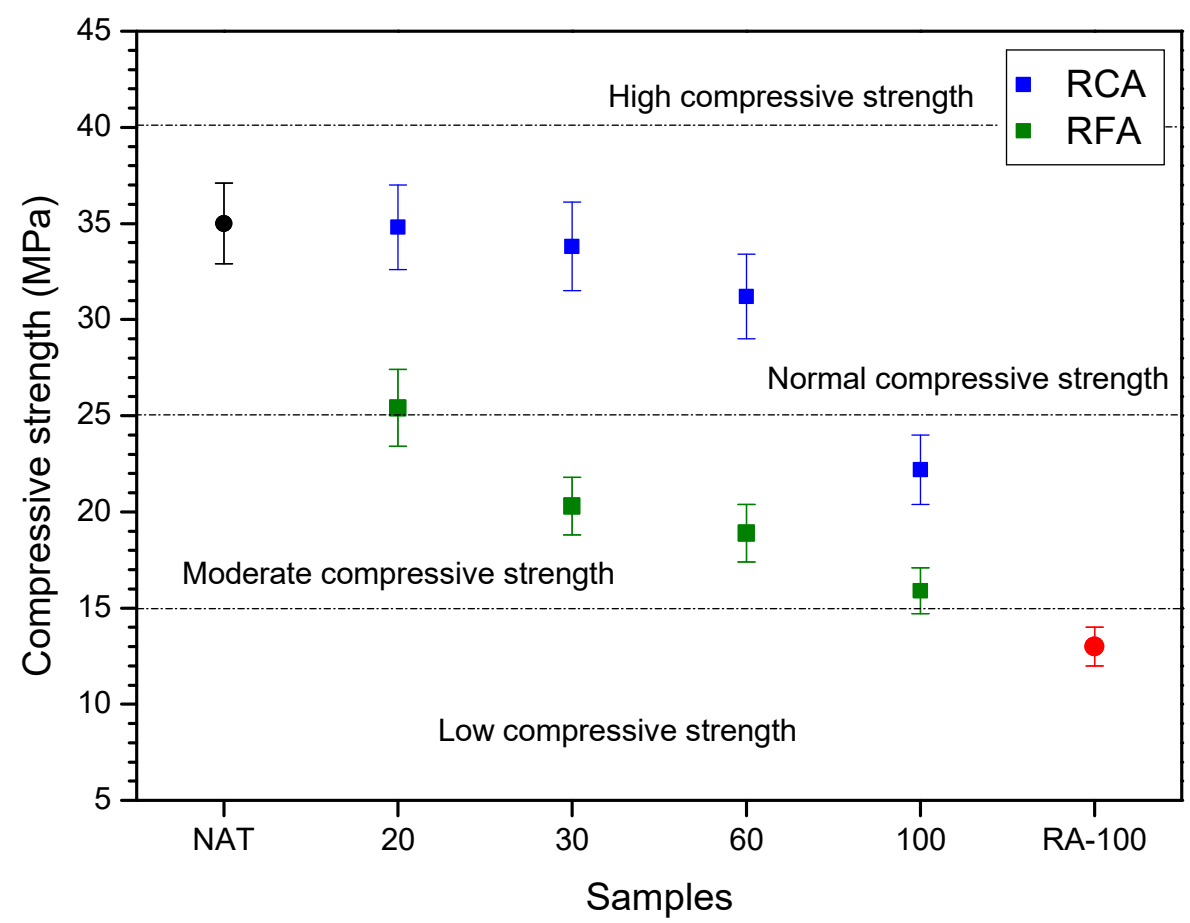

Figure 7. Compressive strength of the studied mixtures.

It can be observed in Figure 7 that as the RCA substitution percentage increases, compressive strength decreases, which is attributed to several factors: to the weaker bonding between the RA and the old mortar adhered to them, to a larger amount of interfacial transition zones (ITZ), to higher absorption and porosity of the RA, and to the old adhered mortar, which gives concrete a porous constitution. It can also be observed that for mixtures with a substitution of RCA up to $60 \%$, strength losses are lower to $10 \%$, so from a mechanical point of view they are feasible to use in structural concretes of normal strength. For mixture RCA-100, a 40\% decrease in compressive strength is reported, reaching values of about $22 \mathrm{MPa}$, which is considered as concrete of moderate strength. Regarding RFA, losses of compressive strength ranging from 15\% (for RFA-20) to over 50\% (RFA-100) are reported. Similar trends have been found in other investigations [10,24-27].

In [26], concretes made with $25 \%$ and $100 \%$ of RFA present reductions of $15 \%$ and $30 \%$ in compressive strength. On the other hand, Evangelista and de Brito [28] conclude that the compressive strength is not affected by the utilization of RFA up to $30 \%$, although the splitting tensile strength and static modulus decrease as the recycled aggregate content increases. 


\subsection{Total Porosity}

Porosity results for the ten mixtures under study are presented in Figure 8. In the case of mixtures with RCA, it can be seen that for percentages of substitution of 20,30, and 60, porosity does not vary significantly $(2 \%, 4 \%$, and $11 \%$, respectively) with respect to the reference mixture (NAT) values. Porosity of the RCA-100 mixture is $125 \%$ higher than the NAT mixture. Regarding the mixtures with RFA, it can be observed that in RFA-20 the porosity increases $41 \%$, while for RFA-30, RFA-60, and RFA-100, the porosity increases $65 \%, 91 \%$, and $98 \%$, respectively, with respect to NAT. The other reference mixture (RA-100) has a $138 \%$ higher porosity.

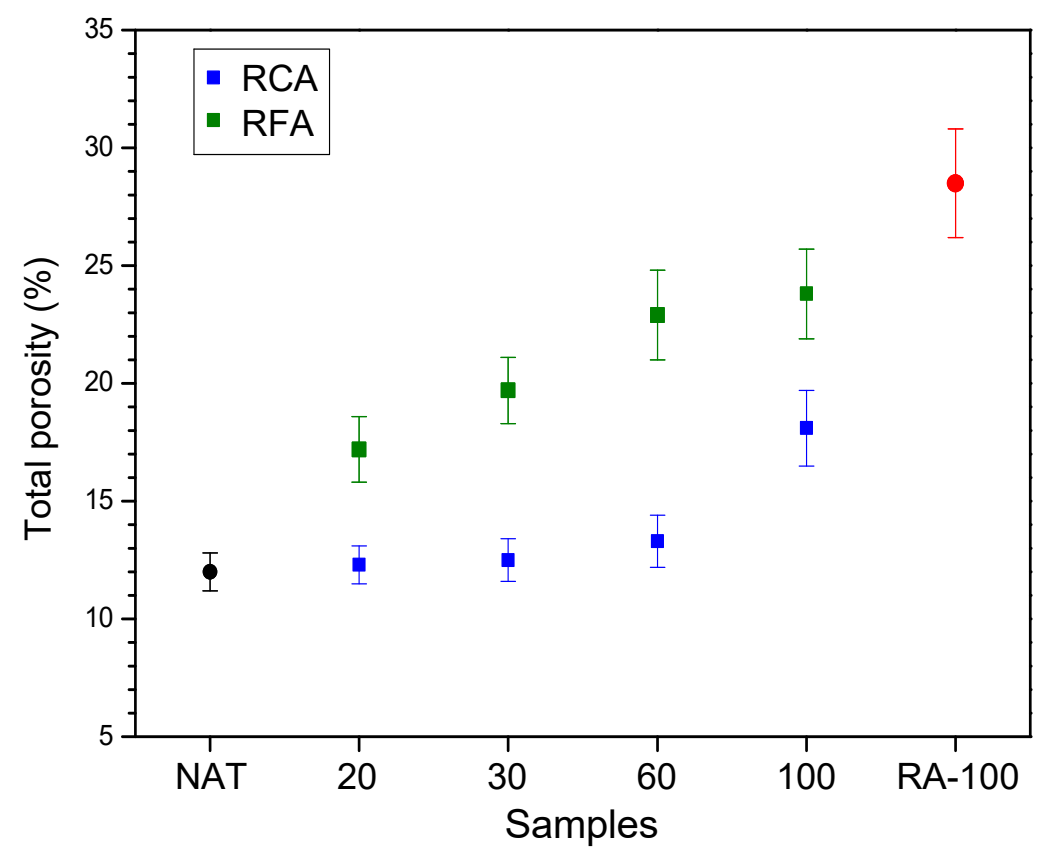

Figure 8. Total porosity of the studied mixtures.

This result indicates that RAC is usually more porous and has greater ability to absorb water, and this is attributed to the high absorption and the porous nature of the old mortar adhered to the RCA and RFA.

As shown in Table 2, in comparison with natural aggregates, RA are more porous and old cement paste is attached on their surface. Thus, the microstructure of ITZ in RAC is different from that in conventional concrete [29], and the total porosity and the average porosity diameter of the concrete increases as the RA content increases [10,30].

In some investigations $[10,24]$, similar values and trends of porosity were found as a function of RCA amount in concrete. In other works [27,31,32], it was found that in concrete with RFA, the amount of water absorbed (implicit porosity) increases.

\subsection{Electrical Resistivity of Concrete}

The $\rho$ as a function of the exposure time shown in Figures 9 and 10 confirms that the use of a certain amount of RA produces increases in the formation of capillary porosity (continuous conductive routes) and consequently lower electrical resistivity. This suggests that there is greater susceptibility to corrosion of steel embedded in concrete with higher electrical conductivity.

In Figure 9, at the end of the exposure period, it can be observed that the concrete with 20\% RFA (RFA-20) shows $\rho$ similar to the reference concrete (NAT) of around 20,000 $\Omega-\mathrm{cm}$, which according to the criterion established in another publication [33], it would mean a low/insignificant corrosion rate of the reinforcing steel. The system RFA-30 ranges between 5000 and 10,000 $\Omega$-cm and for the other 
systems (RFA-60 and RFA-100) $\rho$ oscillates between 6000 and $3000 \Omega$-cm; these values of $\rho$ indicate that the reinforcing steel would have a high and/or very high corrosion rate.

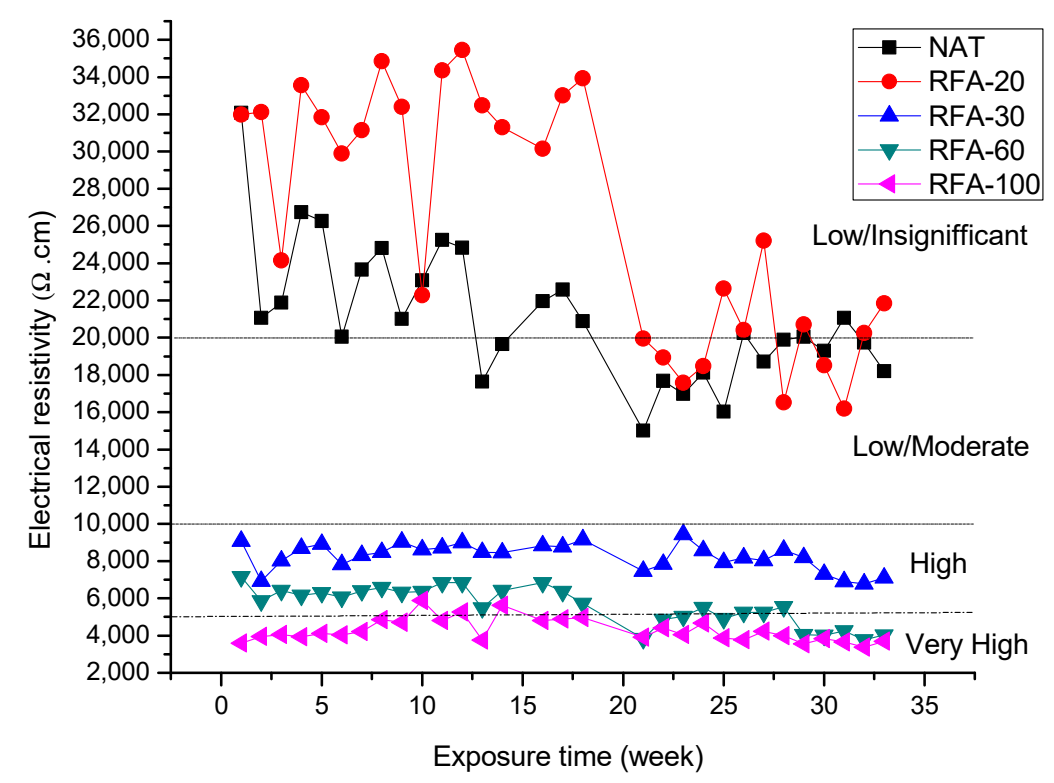

Figure 9. Evolution of $\rho$ for the mixtures with RFA.

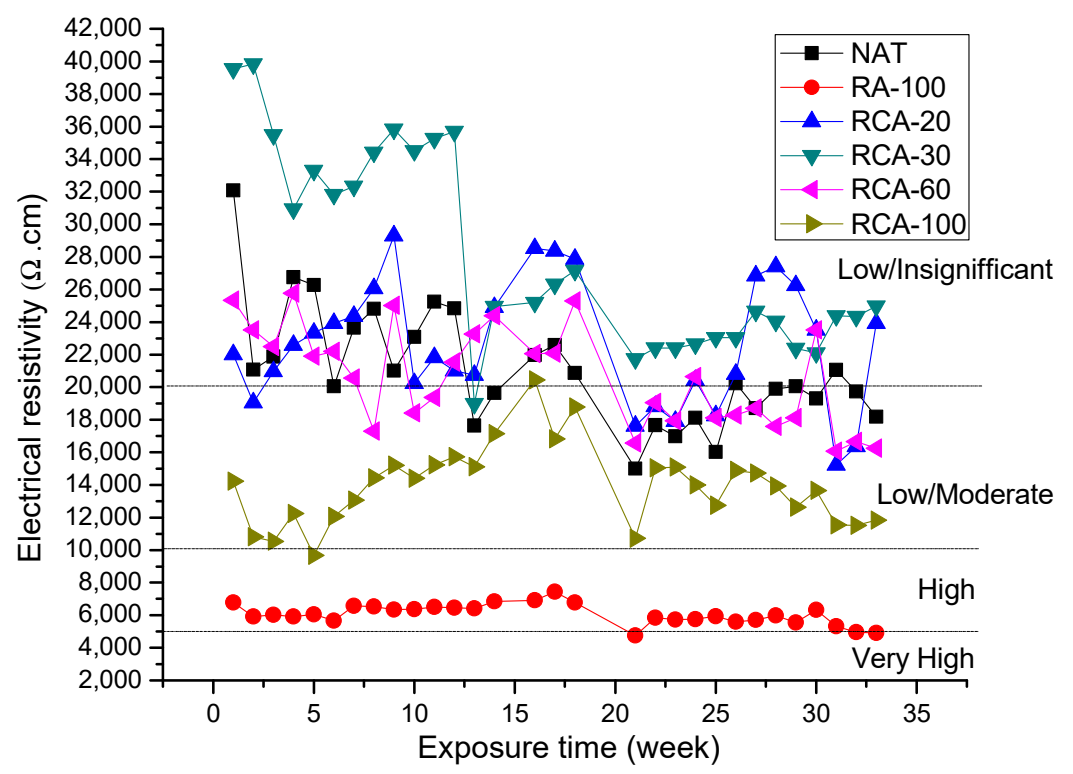

Figure 10. Evolution of $\rho$ for the mixtures with RCA.

In Figure 10 it can be seen that at the end of the exposure period, mixtures RCA-20, RCA-30, and RCA-60 have $\rho$ very similar to the reference mixture (NAT) of around 20,000 $\Omega$-cm, which suggests that the reinforcing steel would be experiencing corrosion at a low/insignificant speed. The RCA-100 mixture has $\rho$ oscillating around $10,000 \Omega-\mathrm{cm}$, which would mean a moderate reinforcement corrosion rate. The RA-100 mixture is the lowest $\rho$ with values ranging between 5000 and $6000 \Omega-\mathrm{cm}$, which means that the reinforcing steel would have a high or very high corrosion rate.

In general, for percentages of RCA over $60 \%$ and RFA over $20 \%$ there is a significant decrease of $\rho$, which means less durability of the system as $\rho$ is closely linked to the concrete continuous porosity. The observed decrease of $\rho$ is attributed to the concrete effective porosity (continuous pores where ionic conductivity takes place) is increased due to the porous nature of the RCA and presumable appearance of new ITZ. 
In Figures 9 and 10, the observed drop of $\rho$ around week 20 is attributed to the fact that in this week the first significant microcracks of the concrete were generated by the expansion of the oxides in the vicinity of the reinforcing steel. The most pronounced fall can be seen in the NAT, RFA-20, RCA-20, and RCA-30 systems, as they are the most resistive. This is corroborated by the notorious increments of $i_{\text {corr }}$ for the same systems and in the same week 20, as shown in Figures 11 and 12.

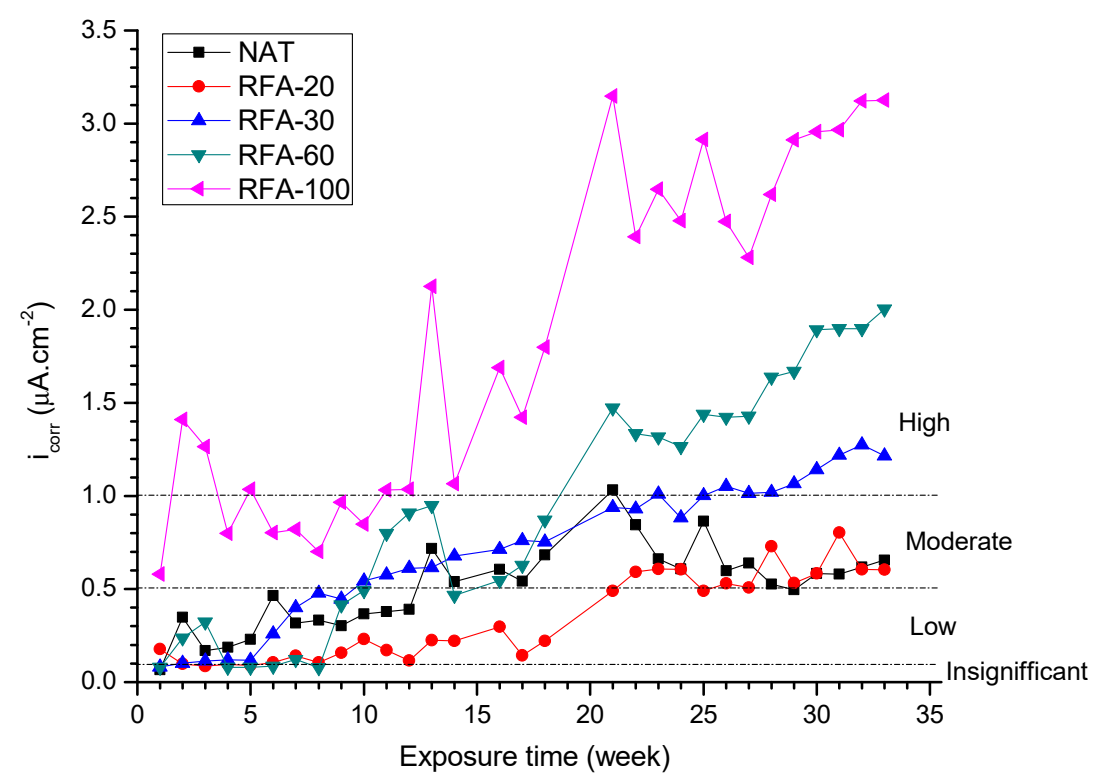

Figure 11. Evolution of $\mathrm{i}_{\text {corr }}$ for mixtures with RFA.

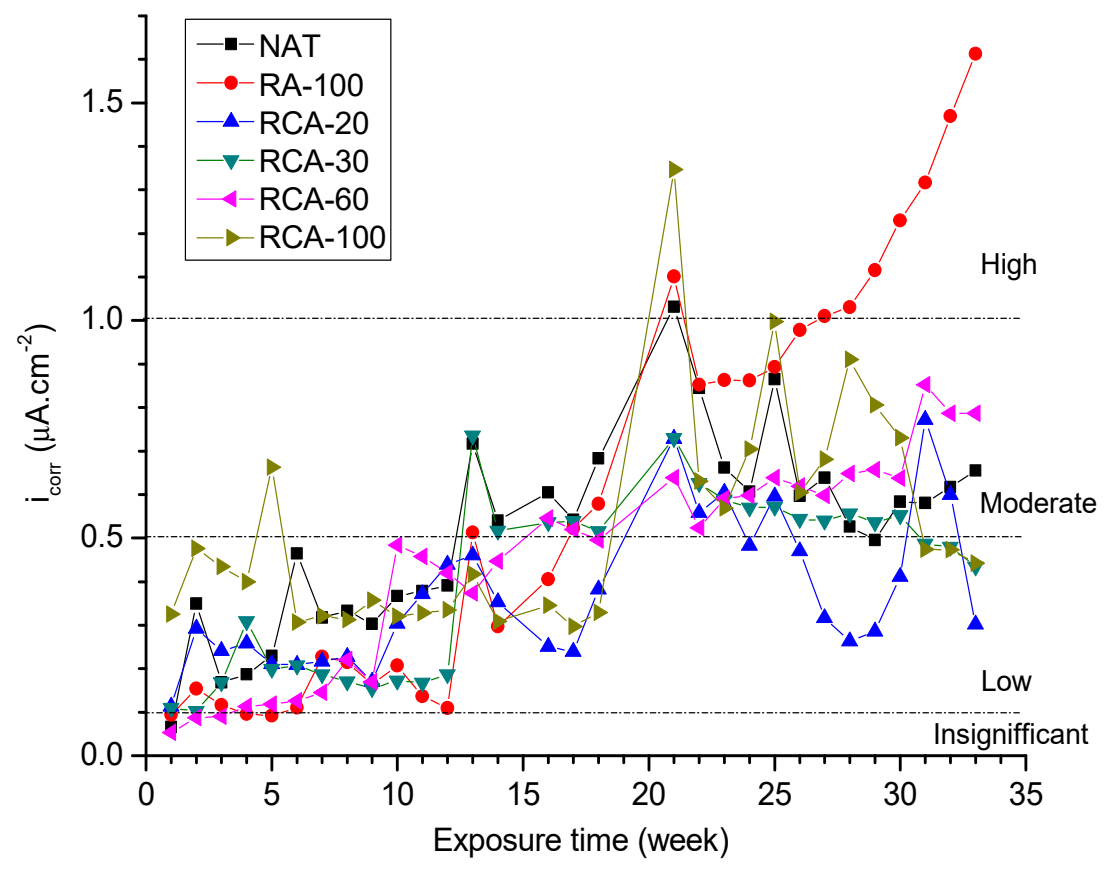

Figure 12. Evolution of $i_{\text {corr }}$ for mixtures with RCA.

In [34] it was found that concrete with 50\% RCA has durability properties (electrical resistivity, sorptivity, chloride-ion penetration) similar to conventional concrete. In [35] it was found that concrete with up to $30 \%$ RFA does not detract from its durability measured with different indicators, such as carbonation depth and sorptivity. These results, although they are different durability indicators, are consistent with those found in the present work. 


\subsection{Corrosion Current Density of Reinforcement Steel}

The $i_{\text {corr }}$ results are presented in Figures 11 and 12, allowing comparison of the corrosion resistance of the steel-concrete systems under study. It can be seen from Figure 11 that the system with $20 \%$ RFA (RFA-20) and the reference system (NAT) exhibit a similar electrochemical behavior keeping at a moderate corrosion level ( $\mathrm{i}_{\text {corr }}$ values between 0.5 and $\left.1.0 \mu \mathrm{A} / \mathrm{cm}^{2}\right)$ until the end of the exposure time and a low corrosion level ( $i_{\text {corr }}$ values between 0.5 and $\left.1.0 \mu \mathrm{A} / \mathrm{cm}^{2}\right)$ in the first weeks of exposure. In the systems with $30 \%, 60 \%$, and $100 \%$ of RFA there is a significant increase of $i_{\text {corr }}$ from week 7,11 , and 12, respectively, (they changed from a low corrosion level to moderate).

The corrosion risk limits shown in Figures 11 and 12 were established in a previous report [33].

Figure 12 shows that systems with $20 \%, 30 \%$, and $60 \%$ of RCA have an electrochemical behavior very similar to the reference system (NAT), maintaining at all times a level of corrosion between low and moderate $\left(\mathrm{i}_{\text {corr }}\right.$ lower than $\left.1.0 \mu \mathrm{A} / \mathrm{cm}^{2}\right)$. Since the beginning of exposure time, the system RCA-100 shows higher values of the other systems, including in week 21 and 25 where it reached the high corrosion level, maintaining its $i_{\text {corr }}$ above the other RCA systems until the end of the evaluation period. In the system with $100 \%$ RA (RA-100), $i_{\text {corr }}$ increased significantly in week 13 , reaching high values of corrosion (greater than $1.0 \mu \mathrm{A} / \mathrm{cm}^{2}$ ); as of week 17 , $\mathrm{i}_{\text {corr }}$ maintained a very steep upward trend.

In general, it can be noted in Figures 9-12 that $\rho$ elucidates in a more clear way the effect of the RA in ionic conductivity of species in concrete because it is not susceptible to dissolved oxygen concentration, nor the surface state, type, and shape of the reinforcement steel oxides; which does not happen with $i_{\text {corr }}$ and therefore the variability of results in the first weeks and between the passive state systems.

The results show that the more RA a concrete mixture contains, the higher the steel corrosion rate is. The presence of RA increases the porosity of concrete and increases the number of types of interfaces in the concrete, both of which make it easier for harmful materials such as chloride to penetrate the concrete. Thus, the higher the RA replacement percentage in RAC is, the higher the steel corrosion rate is. Also, the introduction of a low amount of RA (around 30\% RCA or 20\% RFA) does not increase the rate of steel corrosion significantly. In other publications $[36,37]$ similar results were found.

In [36] $i_{\text {corr }}$ was measured under similar conditions (under humectation-drying cycles) and values and trends similar to those obtained in the present work were found. It can also be seen in this study that due to the resistive nature of the concrete, the sensitivity of the LPR technique and other variables, the standard deviation of the measurements is large (around $0.1 \mu \mathrm{A} / \mathrm{cm}^{2}$ ). In the present work, slightly higher $i_{\text {corr }}$ values were obtained because during the drying period the specimens were exposed to $40{ }^{\circ} \mathrm{C}$ in an oven generating more extreme conditions (in [36], during the drying periods, the specimens were exposed to the air in the laboratory).

\section{Conclusions}

The following conclusions can be drawn from the results of this study considering the proposed dosages.

1. The use of $30 \%$ or lower amounts of RCA does not significantly influence on total porosity and compressive strength. After $30 \%$ of RCA in the mixture, the total porosity increases and compressive strength decreases significantly.

2. Corrosion of steel bars initiates more quickly in RAC than in conventional concrete. The more RA the RAC contains, the earlier corrosion in the steel begins.

3. The corrosion of steel in conventional concrete and RAC accelerates with time. The more RA the RAC contains, the more rapidly the steel corrodes.

4. The use of RA introduces more interfaces in concrete, which accelerates the steel corrosion process because the porosity increases and the electrical resistivity decreases.

5. Steel corrosion and the electrical resistivity in concrete are not significantly influenced by replacing a maximum $30 \%$ of coarse aggregate with RCA. 
6. Steel corrosion and the electrical resistivity in concrete are not significantly influenced by replacing a maximum $20 \%$ of fine aggregate with RFA.

7. Within the limitations and scatter of the present experiments, the degradation of durability parameters occurs with all RA specimens but is significantly greater where the RCA replacement is $>30 \%$ and where the RFA is $>20 \%$.

\section{Future Research}

To correctly understand the corrosion results, capillary suction and mercury intrusion porosimetry measurements should be done, because they will influence strongly the corrosion rates in reinforced concrete. The cell constant used to calculate electrical resistivity must be determined as a function of the geometry and conditions of the conducting body and experimental arrangement.

Author Contributions: S.P.A.-R. and R.C.-H. wrote and edited the paper together; J.M.G.-S. and J.M.B.-C. revised the article; C.A.R.-C. and M.J.U.-N. performed the experiments; R.C.-H. and S.P.A.-R. supervised the research activities and provided guidance and suggestions for the proposed framework and the paper; D.C.G.-G. performed the experiments of aggregates characterization and mechanical properties; all the co-authors contributed to the discussion of the results and preparation of the manuscript.

Funding: This research was funded by DGIP-UAS (PROFAPI 2012/046) and by CONACYT. The APC was funded by program for publication expenses of SEP-PRODEP 2019.

Conflicts of Interest: The authors declare no conflict of interest.

\section{References}

1. Olorunsogo, F.; Padayachee, N. Performance of recycled aggregate concrete monitored by durability indexes. Cem. Concr. Res. 2002, 32, 179-185. [CrossRef]

2. Salinas, M.A.; Macht, A.; Guevara, E.R. El manejo de los residuos de la construcción en el estado de México en el marco de la cooperación técnica alemena en México. DELOS 2008, 1, 6.

3. Page, C.L.; Short, N.R.; EL Tarras, A. Diffusion of Chloride Ions in Hardened Cement Paste. Cem. Concr. Res. 1981, 11, 395-406. [CrossRef]

4. Tuutti, K. Corrosion of Steel in Concrete; Swedish Cement and Concrete Research Institute: Stockholm, Sweden, 1982.

5. Xiao, J.; Lu, D.; Ying, J. Durability of Recycled Aggregate Concrete: An Overview. J. Adv. Concr. Technol. 2013, 11, 347-359. [CrossRef]

6. Baroghel-Bouny, V.; Sato, R.; Fujimoto, Y.; Dohi, T. Durability indicators: A basic tool for performance-based evaluation and prediction of reinforced concrete durability. In Proceedings of the International Seminar on Durability and Life Cycle Evaluation of Concrete Structures, Hiroshima, Japan, September 2004.

7. Wenner, F. A method for measuring earth resistivity. J. Wash. Acad. Sci. 1915, 5, 561-563. [CrossRef]

8. Alonso, C.; Andrade, C.; González, J.A. Relation between resistivity and corrosion rate of reinforcements in carbonated mortar made with several cement types. Cem. Concr. Res. 1988, 189, 687-698. [CrossRef]

9. Bentur, A.; Diamond, S.; Berke, N.S. Steel Corrosion in Concrete: Fundamentals and Civil Engineering Practice; E \& FN Spon CRC Press: London, UK, 1997.

10. Gómez-Soberón, J. Porosity of recycled concrete with substitution of recycled concrete aggregate-An experimental study. Cem. Concr. Res. 2002, 32, 1301-1311. [CrossRef]

11. Poon, C.S.; Shui, Z.H.; Lam, L.; Fok, H.; Kou, S.C. Influence of moisture states of natural and recycled aggregates on the slump and compressive strength of concrete. Cem. Concr. Res. 2004, 34, 31-36. [CrossRef]

12. Etxeberría, M.; Vázquez, E.; Marí, A. Microstructure analysis of hardened recycled aggregate concrete. Mag. Concr. Res. 2006, 58, 683-690. [CrossRef]

13. Tumidajski, P.J.; Shumacher, A.S.; Perron, S.; Gu, P.; Beaudoin, J.J. On the relationship between porosity and electrical resistivity in cementitious systems. Cem. Concr. Res. 1996, 26, 539-544. [CrossRef]

14. Tumidajski, P.J. Relationship between resistivity, diffusivity and microstructural descriptors for mortars with silica fume. Cem. Concr. Res. 2005, 35, 1262-1268. [CrossRef]

15. Polder, R.; Andrade, C.; Elsener, B.; Vennesland, O.E.; Gulikers, J.; Weidert, R.; Raupach, M. Test methods for on site measurement of resistivity of concrete. Mater. Struct. 2000, 33, 603-611. [CrossRef] 
16. Corral-Higuera, R.; Arredondo-Rea, S.P.; Neri-Flores, M.A.; Gómez-Soberón, J.M.; Castorena-González, J.H.; Martínez-Villafañe, A.; Almaral-Sánchez, J.L.; Almeraya-Calderón, F. Chloride Ion Penetrability and Corrosion Behavior of Steel in Concrete with Sustainability Characteristics. Int. J. Electrochem. Sci. 2011, 6, 958-970.

17. Fajardo, G.; Valdez, P.; Pacheco, J. Corrosion of steel rebar embedded in natural pozzolan based mortars exposed to chlorides. Constr. Build. Mater. 2009, 23, 768-774. [CrossRef]

18. Gámez-García, D.C.; Saldaña-Márquez, H.; Gómez-Soberón, J.M.; Corral-Higuera, R. Feasibility study and characterization of aggregates for structural concrete. Ingeniería y Desarrollo 2007, 35, 200-221. [CrossRef]

19. Głuchowski, A.; Sas, W.; Dzięcioł, J.; Soból, E.; Szymański, A. Permeability and Leaching Properties of Recycled Concrete Aggregate as an Emerging Material in Civil Engineering. Appl. Sci. 2019, 9, 81. [CrossRef]

20. Stern, M.; Geary, A. A Theoretical Analysis of the Shape of Polarization Curves. J. Electrochem. Soc. 1957, 104, 56-63. [CrossRef]

21. Deus, J.M.; Díaz, B.; Freire, L.; Nóvoa, X.R. The electrochemical behaviour of steel rebars in concrete: An Electrochemical Impedance Spectroscopy study of the effect of temperature. Electrochim. Acta 2014, 131, 106-115. [CrossRef]

22. Cabeza, M.; Keddam, M.; Nóvoa, X.R.; Sánchez, I.; Takenouti, H. Impedance spectroscopy to characterize the pore structure during the hardening process of Portland cement paste. Electrochim. Acta 2006, 51, 1831-1841. [CrossRef]

23. Torrents, J.M.; Roncero, J.; Gettu, R. Utilization of impedance spectroscopy for studying the retarding effect of a superplasticizer on the setting of cement. Cem. Concr. Res. 1998, 28, 1325-1333. [CrossRef]

24. Dilbas, H.; Simsek, M.; Cakir, O. An investigation on mechanical and physical properties of recycled aggregate concrete (RAC) with and without silica fume. Constr. Build. Mater. 2014, 61, 50-59. [CrossRef]

25. Thomas, C.; Setién, J.; Polanco, J.A.; Alaejos, P.; de Juan, M.S. Durability of recycled aggregate concrete. Constr. Build. Mater. 2013, 40, 1054-1065. [CrossRef]

26. Khatib, J.M. Properties of concrete incorporating fine recycled aggregate. Cem. Concr. Res. 2005, 35, 763-769. [CrossRef]

27. Evangelista, L.; de Brito, J. Durability performance of concrete made with fine recycled concrete aggregates. Cem. Concr. Comp. 2010, 32, 9-14. [CrossRef]

28. Evangelista, L.; de Brito, J. Mechanical behaviour of concrete made with fine recycled concrete aggregates. Cem. Concr. Comp. 2007, 29, 397-401. [CrossRef]

29. Poon, C.S.; Shui, Z.H.; Lam, L. Effect of microstructure of ITZ on compressive strength of concrete prepared with recycled aggregates. Constr. Build. Mater. 2004, 18, 461-468. [CrossRef]

30. Kou, S.C.; Poon, C.S. Compressive strength, pore size distribution and chloride-ion penetration of recycled aggregate concrete. J. Wuhan Univ. Technol. Mater. Ed. Sci. 2006, 21, 130-136.

31. Wirquin, E.; Hadjieva-Zaharieva, R.; Buyle-Bodin, F. Utilisation de l'absorption d'eau des bétons comme critères de leur durabilité-Application aux bétons de granulats recyclés. Mater. Struct. 2000, 33, 403-408. [CrossRef]

32. Levy, S.; Helène, P. Durability of concrete mixed with fine recycled aggregates. Exacta 2007, 5, 25-34. [CrossRef]

33. Bungey, J.H.; Millard, S.G.; Grantham, M.G. Testing of Concrete in Structures, 4th ed.; Taylor \& Francis: New York, NY, USA, 2006.

34. Andreu, G.; Miren, E. Experimental analysis of properties of high performance recycled aggregate concrete. Constr. Build. Mater. 2014, 52, 227-235. [CrossRef]

35. Zega, C.J.; di Maio, A.A. Use of recycled fine aggregate in concretes with durable requirements. Waste Manag. 2011, 31, 2336-2340. [CrossRef] [PubMed]

36. Zhao, Y.; Dong, J.; Wu, Y.; Wang, H.; Li, X.; Xu, Q. Steel corrosion and corrosion-induced cracking in recycled aggregate concrete. Corros. Sci. 2014, 85, 241-250. [CrossRef]

37. Dodds, W.; Christodoulou, C.; Goodier, C.; Austin, S.; Dunne, D. Durability performance of sustainable structural concrete: Effect of coarse crushed concrete aggregate on rapid chloride migration and accelerated corrosion. Constr. Build. Mater. 2017, 155, 511-521. [CrossRef]

(C) 2019 by the authors. Licensee MDPI, Basel, Switzerland. This article is an open access article distributed under the terms and conditions of the Creative Commons Attribution (CC BY) license (http:/ / creativecommons.org/licenses/by/4.0/). 